\title{
Lean Hospital Management, Studi Empirik pada Layanan Gawat Darurat
}

\author{
Indrianawati Usman \& Mira Ardiyana \\ Universtas Airlangga \\ Email: indrianawati-u@feb.unair.ac.id
}

\begin{abstract}
This research focuses on implementing lean management in hospital service, in order to elimination of waste to make a better performance. It's a qualitative single case study research. This study will identified waste and show how to reduce waste using lean management by empirically research in intensive care unit of Islamic hospital in Surabaya. Quantitative tools and measurement also used in this research using value stream analysis tools, and process activity mapping in order to identify the value added and non value added activities. The results of the analysis indicate that there are seven kind of waste. Next the value stream analysis and process activity mapping show that the most frequent waste that cause ineffective performance of hospital service are waiting time, service defect and inappropriate process.
\end{abstract}

Keywords: Lean management, lean hospital, waste, value stream analysis tools, process activity, process activity mapping, value added and non value added activity. 


\section{Indrianawati Usman \\ Mira Ardiyana}

\section{LATAR BELAKANG}

Pelayanan kesehatan yang bermutu adalah yang dapat memuaskan setiap pemakai jasa layanan yang sesuai dengan tingkat kepuasan rata-rata penduduk serta penyelenggaraannya sesuai dengan standart dan kode etik profesi yang telah ditetapkan. Salah satu cara dalam memberikan pelayanan yang baik bagi konsumen dapat diwujudkan apabila rumah sakit mampu mengelola sumberdaya yang tersedia didalam rumah sakit dan memaksimalkannya (Graban 2009). Sejalan dengan bertambahnya jumlah rumah sakit maka tingkat persaingan layanan rumah sakit juga semakin meningkat, ditambah dengan semakin tingginya standar tuntutan masyarakat akan layanan kesehatan. Permasalahan yang dihadapi oleh rumah sakit adalah kualitas pelayanan yang kurang, proses menunggu pasien di emergency room yang terlalu lama, kurangnya pekerja untuk melayani pasien, pekerja yang mengalami kesulitan dengan alat-alat yang baru. Selanjutnya dinyatakan bahwa yang dapat mengatasi masalah tersebut adalah metode lean. Konsep lean mulai muncul tahun 1950-an, dan diadaptasi oleh banyak perusahaan untuk meningkatkan value added (nilai tambah) dan meminimalisir waste (pemborosan) yang terjadi dalam industri. (Gaspers.V \& Fontana.A. 2011) menyatakan rasio antara value added terhadap waste pada perusahaan-perusahaan Jepang rata-rata mencapai 50\%, Toyota Motor sekitar 57\%, perusahaan-perusahaan terbaik di Kanada dan Amerika Serikat sekitar 30\%, sedangkan perusahaan terbaik di Indonesia masih $10 \%$.

Konsep lean yang diterapkan di industri disebut lean manufacturing, sedangkan lean yang diterapkan di rumah sakit disebut lean hospital. Lean Hospital dibutuhkan agar Rumah Sakit dapat memenuhi kebutuhan pasien secara optimal, dapat memberikan pelayanan kesehatan semaksimal mungkin kepada pasien dengan mengurangi waste (pemborosan) yang pada akhirnya akan menciptakan nilai tambah bagi Rumah Sakit. Penelitian ini merupakan penelitian kualitatif dengan pendekatan single case study. Tools yang digunakan untuk megidentifikasikan pemborosan adalah "Big picture mapping" yang menggambarkan seluruh aktivitas dan lead time nya secara skematis. Penggunaan tehnik lean telah banyak dilakukan untuk perusahaan jasa, termasuk jasa rumah sakit. Terdapat beberapa pemanfaatan lean perusahaan jasa. antara lain untuk upgrade quality, Clarify process flow, Revise Equipment and Process technology, level of facility load and Elimnate unnecessary activity. Penelitian ini akan memfokuskan penmanfaatan lean hospital untuk meniadaan aktivitas yang tidak perlu. Berikut adalah pernyataan (Chase.R.B 2018)

...Eliminate unnecessary activities, step that does not add value is candidate for elimination. A step that does added value may be candidate for reengineering to improve the process consistency or to reduce the time to perform the task.

Penelitian ini bertujuan untuk mengidentifikasikan pemborosan yang terjadi dalam proses layanan kesehatan, khususnya pada layanan yang terdapat dalam unit gawat darurat sebuah rumah sakit. Selanjutnya penelitian ini juga bertujuan untuk meniadakan pemborosan yang terjadi dengan metode lean hospital. 


\section{Jurnal Manajemen Teori dan Terapan}

Tahun 10. No. 3, Desember 2017

\section{TINJAUAN PUSTAKA}

Dasar pemikiran "Lean" bermula dari konsep produksi Just in time (JIT) yang diterapkan oleh Toyota sebagai pionirnya. (Chase.R.B 2018) menyatakan bahwa:

Lean Production is an integrated activities designed to achieve high-volume, high quality production using minimal inventories or raw materials, work in process and finished good

Lean merupakan suatu upaya terus-menerus untuk menghilangkan waste (pemborosan) dan meningkatkan value added (nilai tambah) produk barang maupun jasa agar memberikan customer value. Tujuan lean adalah untuk meningkatkan customer value melalui peningkatan terus menerus rasio antara nilai tambah terhadap waste (Gaspers.V \& Fontana.A. 2011).

Terdapat lima prinsip lean, dalam Lean Six Sigma terdapat lima prinsip lean, (Gaspers.V \& Fontana.A. 2011) yaitu:

1. Mengidentifikasi nilai produk (barang atau jasa) berdasarkan perspektif pelanggan, dimana pelanggan menginginkan produk yang berkualitas, dengan harga yang kompetitif, dan penyerahannya tepat waktu.

2. Mengidentifikasi value stream process mapping (pemetaan proses pada value stream) untuk setiap produk (barang dan atau jasa).

3. Menghilangkan waste (pemborosan) yang tidak bernilai tambah dari semua aktivitas sepanjang proses value stream itu.

4. Mengorganisasikan agar material, informasi, dan produk itu mengalir secara lancar dan efisien sepanjang proses value stream menggunakan pull system.

5. Terus menerus mencari berbagai teknik dan alat peningkatan untuk mencapai keunggulan dan peningkatan terus-menerus.

\section{Lean Hospital}

Lean Hospital adalah suatu aturan yang merupakan suatu sistem manajemen dan juga suatu filosofi yang dapat merubah cara pandang suatu rumah sakit agar lebih teratur dan teroganisir dengan memperbaiki kualitas layanan untuk pasien dengan cara mengurangi kesalahan dan mengurangi waktu tunggu (Graban 2009). Metode lean yang digunakan rumah sakituntuk memperbaiki kualitas layanan terhadap pasien dengan mengurangi dua permasalahan utama yaitu mengurangi kesalahan (reducing errors) dan waktu tunggu (waiting time). Dalam dua definisi diatas dapat disimpulkan bahwa Graban mendefinisikan lean menjadi dua hal, yaitu:

\section{Total Elimination Waste}

Pemborosan, muda, atau waste merupakan segala aktivitas yang tidak mencerminkan bantuan dalam proses penyembuhan terhadap pasien. Semua pemborosan harus dihilangkan atau minimal dikurangi agar dapat menekan biaya rumah sakit, meningkatkan kepuasan pasien, serta meningkatkan keselamatan pasien dan pegawai. Contoh waste yang ada dirumah sakit adalah:

1. Waktu tunggu pasien untuk diperiksa oleh dokter

2. Waktu tunggu untuk proses berikutnya

3. Adanya kesalahan yang membahayakan pasien 


\section{Indrianawati Usman}

\section{Mira Ardiyana}

4. Pergerakan yang tidak perlu, misal letak apotik dan kasir yang terlalu jauh

\section{Respect for People}

Respect dalam konteks lean memiliki sejumlah cara untuk mendorong karyawan agar termotivasi untuk melakukan pekerjaan yang lebih baik dengan cara konstruktif dengan cara melakukan respect kepada pasien, karyawa, dokter, dan semua stakeholder yang terdapat dalam rumah sakit beserta lingkungannya. Graban, membuat definisi mengenai 5 prinsip lean yang diadaptasi ke dalam sistem pelayanan di rumah sakit, seperti yang yang terurai pada tabel 1

\begin{tabular}{|l|l|}
\multicolumn{2}{c|}{$\begin{array}{c}\text { Tabel 1 } \\
\text { Prinsip Lean }\end{array}$} \\
\hline Prinsip- Prinsip & Lean Hosptal \\
\hline Value & $\begin{array}{l}\text { Nilai secara spesifik harus dilihat dari sudut pandang } \\
\text { konsumen akhir (pasien) }\end{array}$ \\
\hline Value Stream & $\begin{array}{l}\text { Identiifkasi semua tahapan proses yang memberikan } \\
\text { nilai tambah pada semua dan lintas departemen (the } \\
\text { value stream), hilangkan tahapan-tahapan yang tidak } \\
\text { menciptakan nilai }\end{array}$ \\
\hline Flow & $\begin{array}{l}\text { Menjaga agar proses berjalan lancar dengan } \\
\text { menghilangkan faktor-faktor penyebab masalah } \\
\text { kualitas layanan atau pengalokasian sumber daya }\end{array}$ \\
\hline Pull & $\begin{array}{l}\text { Hindari mendorong suatu pekerjaan berdasarkan } \\
\text { ketersediaan sumber daya yang ada, biarkan suatu } \\
\text { proses jasa terjadi karena adanya kebutuhan atau } \\
\text { suatu permintaan dari pasien (sehingga tercipta } \\
\text { efisiensi dan kesesuaian dengan kebutuhan pasien) }\end{array}$ \\
\hline Perfection & $\begin{array}{l}\text { Kejar kesempurnaan pelayanan melalui perbaikan } \\
\text { berkelanjutan }\end{array}$ \\
\hline
\end{tabular}

\section{Unsur-Unsur Lean Hospital}

\section{Waste}

(Womack, James. P and Jones 2000) menyebutkan bahwa pemborosan atau waste dalam bahasa Jepang disebut muda yaitu merupakan segala suatu tindakan yang dilakukan tanpa menghasilkan nilai. Contoh bentuk dari waste adalah perbaikan yang dilakukan karena adanya kesalahan, produksi barang yang tidak diingingkan konsumen, penumpukan inventori, tahap proses yang tidak terlalu dibutuhkan, perpindahan orang atau bahan yang tidak perlu dari suatu tempat ke tempat lain, menunggu akibat pengantaran yang tidak tepat waktu, dan seluruh barang dan jasa yang tidak sesuai di mata konsumen (Womack, James. P and Jones (2000).

\section{Waste in Hospital}

Permasalahan dan gangguan yang muncul secara konstan, yang menggangu pekerjaan dan pelayanan pasien disebut waste atau pemborosan (Graban n.d.,2009). Dalam buku milik Mark Graban berjudul Lean Hospital, menunjukkan bahwa karyawan rumah sakit secara tipikal menghasilkan sebuah presentase yang tinggi dari waktu mereka dalam 


\section{Jurnal Manajemen Teori dan Terapan}

Tahun 10. No. 3, Desember 2017

pemborosan aktivitas seperti seorang suster medis di rumah sakit di dunia hanya menggunakan 25-50\% waktu mereka dalam melakukan layanan kepada pasien secara langsung seperti mengecek status pasien, administrasi pengobatan, menjawab pertanyaan pasien, dan memberikan panduan medis.

\section{Overproduction}

Waste overproduction di dalam proses pelayanan rawat jalan dan rawat inap yang melitputi mengeluarkan hasil tes laboratorium berulang-ulang dengan informasi yang sama.

2. Waiting

Waste waiting terjadi ketika pasien menunggu untuk proses selanjutnya di ruang tunggu yakni menunggu periksa dokter menunggu proses administrasi menunggu hasil tes di laboratorium, menunggu dokumen, specimen yang menunggu untuk di tes, menunggu pembayaran obat, menunggu obat farmasi.

3. Unnecessary Transportation

Unnecessary transportation dalam pelayanan rawat jalan dan rawat inap meliputi, perpindahan pasien yang berlebih dan mengambil berkas yang letaknya jauh yakni pengiriman berkas rekam medis ke tempat periksa.

4. Overprocessing

Overprocessing pada instalasi rawat jalan dan instalasi rawat inap yakni pencatatan identitas pasien dilakukan berulang-ulang, yakni pada dokumen rekam medis, buku register, kartu kendali, dan komputer.

5. Unnecessary Inventory

Unnecessary Inventory yang terjadi adalah persediaan obat yang berlebih, persediaan peralatan laboraturium yang berlebih, dokumen yang masih diproses yakni penumpukan dokumen pasien, dan persediaan peralatan rumahsakit yang berlebih yakni kartu rekam medis yang belum terpakai.

6. Unnecessary Motion

Unnecessary motion yang terjadi yakni mencari dokumen rekam medis, mengumpulkan peralatan medis, adanya gerakan yang tidak diperlukan pada bagian informasi dan pendaftaran untuk menjangkau barang-barang seperti mencari kuitansi alat tulis atau mencari obat.

7. Defect

Defect terjadi baik di rawat inap maupun instalasi gawat darurat yakni seperti salah memberi obat, dokter mengganti resep yang telah dibuat pada pasien karena obat pada resep sebelumnya tidak ada dalam farmasi, ketidak kelengkapan kebutuhan pasien untuk administrasi, dan pasien dibawa ke ruang pemeriksaan yang salah.

8. Underutilized abilities of people

Waste underutilized abilities of people yakni dokter kurang memberikan edukasi pada pasien, perawat di Instalasi Gawat Darurat kurang memberikan perhatian yang optimum kepada pasien..

\section{Tujuan dan Manfaat Lean Hospital}

Tujuan dari Lean Hospital sendiri adalah untuk meningkatkan customer value yaitu pasien melalui peningkatan terus menerus rasio antara nilai tambah terhadap waste (the value to waste-ratio). Banyak rumah sakit di seluruh dunia yang telah menerapkan Lean Hospital dan menghasilkan banyak manfaat. Diantaranya mengurangi waktu tunggu pasien, meningkatkan kualitas pelayanan terhadap pasien, meningkatkan nilai keterlibatan karyawan dan dapat mendeteksi waste yang terjadi di rumah sakit sehingga dapat 


\section{Indrianawati Usman \\ Mira Ardiyana}

meminimalkan biaya operasional. (Graban 2009) mengungkapkan beberapa contoh keberhasilan lean dalam meningkatkan efektivitas dan efisiensi kinerja pada rumah sakit, diantaranya yaitu:

1. Penurunan turn around time hasil labolatorium klinis sebesar $60 \%$ pada Alegent Health, Nebraska.

2. Penurunan dekontaminasi dan cycle time sterilisasi alat-alat sampai $70 \%$ pada Kingston General Hospital, Ontario

3. Penurunan angka kematian pasien berkaitan dengan infeksi saluran darah sampai dengan 95\% pada Allegheny Hospital, Pennsylvania.

4. Pengurangan waktu tunggu pasien untuk bedah ortophedic dari 14 minggu menjadi 31 jam, pada Theda Care, Wisconsin.

5. Peningkatan Surgical revenue sebesar $\$ 808.000$ per tahun, pada Ohio Health, Ohio.

6. Pengurangan LOS sebesar $29 \%$ dan terhindar $\$ 1,25$ juta dalam pembangunan unit gawat darurat baru, pada Avera Mc Kennan, South Dakota.

7. Hemat \$7,5 dari Lean Rapid Improvement Event pada tahun 2004 dan menginvestasikan kembali ke dalam perawatan pasien di Park Nocollet Health Service, Medical.

\section{Value Stream Mapping Tools}

Valve Stream Analysis Tools adalah tools yang dikembangkan oleh (Hines, P., \& Rich 1997) untuk mempermudah pemahaman dari value stream yang sudah dibuat dan membantu dalam proses perbaikan pemborosan yang ada di dalam value stream. Valve stream mapping (VSM) merupakan alat (diagram) yang digunakan untuk membantu dalam melihat dan memahami aliran dari material dan informasi suatu produk di dalam value stream (Mike dan John, 2003). Value Stream Mapping juga dipakai dalam melakukan pemetaan berkaitan dengan aliran produk dan aliran informasi mulai dari pemasok, produsen, dan konsumen dalam suatu gambar untuk meliputi semua proses dalam satu sistem (Agustiningsih 2011). (Gaspers.V \& Fontana.A. 2011) mendefinisikan value stream sebagai proses untuk membuat, memproduksi dan menyerahkan produk ke pasar. Analisis value stream dapat mengidentifikasi tiga jenis aksi sepanjang value stream yaitu:

a. Value-Added, Kegiatan-kegiatan atau proses yang menghasilkan nilai.

b. Necessary but Non Value-Added, Tahap yang tidak menghasilkan nilai namun tidak dapat dihindari dengan teknologi dan sumber daya yang ada.

c. Non Valve-Added, Tahap yang tidak menghasilkan nilai dan bisa dihindari.

Pada tahun 1980-an produsen mobil Toyota menggunakan value strean mapping untuk pertama kalinya yang disebut dengan Material and Information Flow Mapping. Value Stream Mapping mampu memvisualisasikan aliran produk dan mengidentifikassi waste. Valve Stream Mapping juga membantu dalam kegiatan memprioritaskan masalah yang akan diselesaikan. Menurut Liker dalam Ars Agustiningsih, terdapat keuntungan-keuntungan dalam menerapkan value stream, diantaranya adalah:

a. Kualitas yang inheren

b. Menciptakan fleksibilitas yang sebenarnya

c. Menciptakan produktivitas yang lebih tinggi

d. Mengosongkan ruang kerja

e. Meningkatkan keselamatan kerja

f. Semangat kerja yang meningkat

g. Mengurangi biaya persediaan. 


\section{Jurnal Manajemen Teori dan Terapan}

Tahun 10. No. 3, Desember 2017

Menurut(Hines, P., \& Rich 1997) Value stream mapping mempunyai tujuh tools yang dapat digunakan, anatara lain :

\section{Process Activity Mapping}

Tool ini memberikan gambaran aliran fisik dan informasi, waktu yang diperlukan untuk setiap aktivitas, jarak yang ditempuh dan tingkat persediaan produk dalam setiap tahapan produksi. Kemudahan identiifkasi aktivitas terjadi karena adanya penggolongan aktivitas menjadi lima jenis yaitu, operasi, transportasi, inpeksi, delays, dan penyimpanan.

2. Supply Chain Response Matrix

Tool ini merupakan sebuah diagram yang menggambarkan hubungan antara inventory dan lead time pada jalur distribusi, sehingga dapat diketahui adanya peningkatan maupun penurunan tingkat persediaan dan waktu distribusi pada tiap area dalam supply chain. Tool ini juga dapat digunakan sebagai bahan pertimbangan manajemen untuk menaksir kebutuhan stock apabila dikaitkan pencapaian lead time yang pendek. Tools ini digunakan untuk menjaga dan meningkatkan service level kepada konsumen pada tiap jalur distribusi dengan biaya yang rendah.

\section{Production Variety Funnel}

Tool ini merupakan suatu teknik pemetaan visual dengan cara melakukan plot pada sejumlah produk yang dihasilkan dalam setiap manufaktur. Tool ini dapat digunakan untuk mengidentifikasi bagian mana sebuah produk generic diproses menjadi beberapa produk yang spesifik. Dan tool ini juga dapat digunakan untuk mengetahui area bottleneck pada desain proses. Kemudian dapat digunakan untuk merencanakan perbaikan kebijakan inventory dan membuat perubahan pada sebuah produk.

4. Quality Filter Mapping

Tool ini digunakan untuk mengidentifikasi letak permasalahan defect pada kualitas di supply chain. Evaluasi hilangnya kualitas yang sering terjadi dilakukan untuk pengembangan jangka pendek. Masalah kualitas tersebut berupa product defect, scrap defect, dan service defect.

5. Demand Amplification

Tool ini digunakan untuk memvisualisasikan perubahan demand di supply chain dalam interval waktu tertentu. Informasi yang dihasilkan digunakan untuk mengambil keputusan dan melakukan analisa lebih lanjut untuk mengantisipasi terjadinya perubahan demand, mengatur fluktuasi, serta evaluasi kebijakan inventory.

6. Decision Point Analysis

Tool ini memnunjukkan berbagai pilihan sistem produksi yang berbeda, dengan trade off antara lead tme masing-masing pilihan dengan tingkat inventory yang diperlukan untuk meng-cover selama proses lead time.

7. Physical Structure

Tool ini digunakan untuk memahami supply chain di level produksi. Hal ini diperlukan untuk memahami kondisi industri tersebut, bagaimana operasinya, dan dalam mengarahkan perhatian pada area yang belum mendapatkan perhatian yang cukup untuk pengembangan. Penelitian tentang lean hospital merupakan penelitian yang masih jarang dalam dunia manajemen operasi terutama di Indonesia karena perkembangan masyarakat di Indonesia masih berfokus untuk menggunakan lean hanya pada operasi di bidang produksi daripada operasi di bidang jasa. Padahal hal ini sangat penting untuk memperbaiki kinerja jasa, terutama pada pelayanan di rumah sakit. 


\section{Indrianawati Usman Mira Ardiyana}

Beberapa penelitian telah dilakukan berkenaan dengan topic lean hospital seperti yang dilakukan oleh (Kodra 2013) dengan judul Identifikasi Waste (Pemborosan) Serta Usulan Perbaikan di Instalasi Farmasi Dengan Menggunakan Fishbone Diagram dan Lean Hospital di Rumah Sakit Islam Surabaya membahas tentang implementasi lean yang diterapkan di rumah sakit untuk mengidentifikasi waste dan mengimplementasikan lean hospital sebagai usulan perbaikan di instalasi farmasi di Rumah Sakit Islam Ahmad Yani Surabaya. Peneliti menggunakan metode kualitatif dengan menyebar kuisoner importance-performance analysis dan value stream mapping yang memperlihatkan nilai aktivitas yang terdapat di unit farmasi untuk mencari value added, non value added, dan necessary non value added.

(Pertiwi n.d.) tahun 2012 dengan judul Lean Hospital Sebagai Usulan Perbaikan Sistem Rack Addressing dan Order Picking Gudang Logistik Perbekalan Kesehatan Rumah Sakit Islam Jakarta Cempaka Putih membahas tentang penerapan lean hospital untuk meningkatkan produktivitas. Peneliti mempelajari bagaimana lean hospital dapat diusulkan sebagai ide perbaikan untuk menyelesaikan permasalahan di gudang perbekalan kesehatan Rumah Sakit Islam Jakarta Cempaka Putih yang dikarenakan terdapat banyak pemborosan dimana hal tersebut merupakan kegiatan yang tidak memiliki nilai tambah untuk kepuasan pelanggan.

\section{Research Question}

\begin{tabular}{|c|c|c|}
\hline No & Tema Pertanyaan & $\begin{array}{c}\text { Pertanyaan Penelitian } \\
\end{array}$ \\
\hline 1. & $\begin{array}{l}\text { Mengidentifikasi } \\
\text { pemborosan }\end{array}$ & $\begin{array}{l}\text { 1. Apakah dalam proses pemberian jasa terdapat } \\
\text { vaktu tunggu dari pasien } \\
\text { 2. Apakah dalam proses pemberian jasa terdapat } \\
\text { perumpukan aktivitas yang terjadi } \\
\text { 3. Apakah dalam proses pemberian jasa terdapat } \\
\text { perpindahan yang tidak dipertukan } \\
\text { 4. Apakah dalam proses pemberian jasa terdapat } \\
\text { kesalahan atau kegagalan dalam aktivitas tertentu } \\
\text { 5. Bagaimana melakukan pembobotan untuk } \\
\text { permilihan tools VALSAT }\end{array}$ \\
\hline 2. & $\begin{array}{l}\text { Mengidentifikasi } \\
\text { penyebab }\end{array}$ & $\begin{array}{l}\text { 1. Apa saja penyebab munculnya pemborosan yang } \\
\text { terjadi di dalam proses pelayanan }\end{array}$ \\
\hline 3. & Usulan perbaikan & $\begin{array}{l}\text { 1. Apa usulan yang diberikan untuk mencegah } \\
\text { terjadinya pemborosan }\end{array}$ \\
\hline
\end{tabular}

\section{METHODE PENELITIAN}

Penelitian ini menggunakan pendekatan kualitatif single case studi research untuks mengungkap secara mendalam tentang fakta dalam rangka mengidentifikasikan pemborosan dan mencari solusi untuk mengurangi dan atau menidadakan pemborosan. Riset secara empiris dilakukan pada unit gawat darurat di rumah sakit Islam Surabaya. Alatalat pengukuran kuantitatif juga dimanfaatkan dalam penelitian ini untuk melakukan pengukuran secara tepat berkenaan kengan identifikasi pemborosan dan solusinya, yaitu value stream analiysis tools, process activity mapping untuk mengidentifikasikan value added dan non value added activities. Pengumpulan data dilakukan melalui informasi dengan sumber data. Informan penelitian ini adalah direktur dan kepala unit gawat darurat. 
Selanjuntnya data yang berkenaan dengan proses layanan dikumpulkan melalui penyebaran kuesioner. Data skunder diperoleh dari catatan-catatan rumah sakit, berupa data pasien yang datang ke unit gawat darurat rumah sakit islam Surabaya. Selanjutnya triangulasi dilakukan melalui triangulasi sumber dengan cara membandingkan informasi dari berbagai sumber informasi. Sedangkan teknik analisis yang digunakan merupakan alat untuk mengidentifikasikan pemborosan, yaitu big picture mapping, value stream mapping untuk pembobotan komponen pemborosan yang teridentifikasi dan untuk mengidentifikasikan penyebab † erjadinya pemborosa dilakukan melalui fishbone diagram. Lean hospiital dilakukan untuk memberikan solusi peniadaan waste, dalam hal ini adalah dengan mendiadakan non value added actvities

\section{HASIL PENELITIAN}

Sistem yang efektif dan efisien dilakukan dengan cara menghilangkan non value added activity bagi pelanggan, yang merupakan tujuan utama dari lean. Maka dilakukan penelitian di IGD Rumah Sakit Islam Jemursari untuk menggambarkan bagaimana Big Picture Mapping dari proses layanan jasa tersebut. Big Picture Mapping digunakan untuk mengetahui aktivitas mana saja yang termasuk dalam value added activity dan non value added activity. Penelitian yang dilakukan hanya berfokus pada proses jasa yang dimulai dari pasien datang ke IGD yang dibawa oleh ambulance ataupun datang sendiri hingga pasien keluar dari IGD karena rujukan pulang atau menuju ke kamar rawat inap.

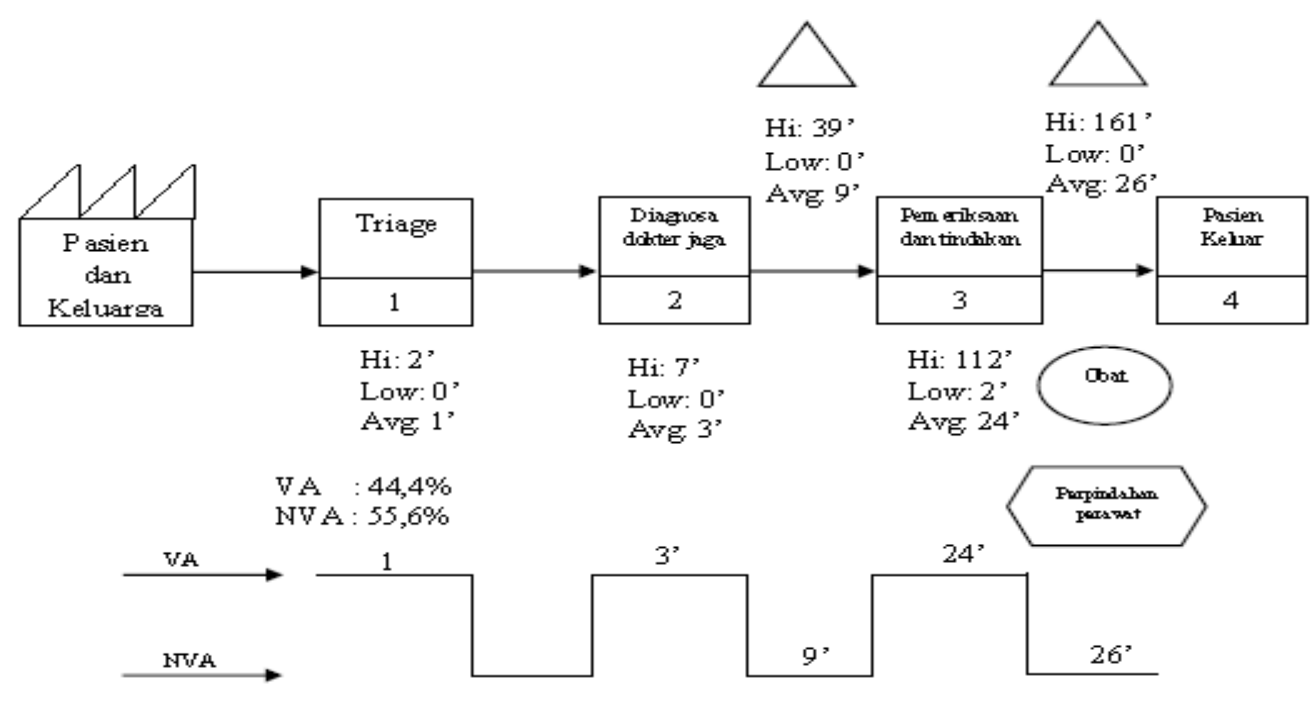

Gambar 1. Big Picture Mapping Penanganan Pasien di IGD

Berdasarkan Big Picture Mapping dari proses penanganan pasien di IGD yang ada diatas, dapat diidentifikasi aktivitas-aktivitas mana saja yang menambah valve dan mana saja aktivitas yang tergolong waste. Selanjutnya data table berikut ini dapat lebih menjelaskan klasifikasi aktivitas yang tergolong value added dan non value added. 
Tabel 2

Identifikasi proses aktivitas proses pelayanan di IGD

\begin{tabular}{|c|l|c|c|c|}
\hline \multirow{2}{*}{ Kode } & \multicolumn{1}{|c|}{ Aktivitas yang dilakukan } & \multicolumn{3}{|c|}{ Tipe Aktivitas } \\
\cline { 3 - 5 } & VA & NVA & NNVA \\
\hline 1 & $\begin{array}{l}\text { Perawat menentukan triage dari } \\
\text { pasien yang datang ke IGD. }\end{array}$ & $\mathrm{X}$ & & \\
\hline 2 & Diagnosa dokter jaga. & $\mathrm{X}$ & & \\
\hline $2 . \mathrm{A}$ & $\begin{array}{l}\text { Keluarga pasien mengisi daftar } \\
\text { administrasi pasien. }\end{array}$ & $\mathrm{X}$ & & \\
\hline 3 & Pemeriksaan dan tindakan & $\mathrm{X}$ & & \\
\hline $3 . \mathrm{A}$ & $\begin{array}{l}\text { Pasien berpindah ke instalasi lain } \\
\text { (laboratorium atau radiologi) }\end{array}$ & & & $\mathrm{X}$ \\
\hline $3 . \mathrm{B}$ & $\begin{array}{l}\text { Menunggu hasil dari instalasi lain } \\
\text { (laboratorium atau radiologi) }\end{array}$ & & $\mathrm{X}$ & \\
\hline $3 . \mathrm{C}$ & $\begin{array}{l}\text { Dokter jaga menj elaskan hasil dari } \\
\text { laboratorium atau radiologi kepada } \\
\text { pasien }\end{array}$ & & $\mathrm{X}$ & \\
\hline $3 . \mathrm{D}$ & Menunggu obat dari apotek & & $\mathrm{X}$ & \\
\hline $3 . \mathrm{E}$ & $\begin{array}{l}\text { Perawat memberikan daftar rincian } \\
\text { obat dan peralatan yang digunakan } \\
\text { pasien ke pihak administrasi }\end{array}$ & $\mathrm{X}$ & & \\
\hline 4 & $\begin{array}{l}\text { Pasien menunggu untuk } \\
\text { diperbolehkan pulang atau berpindah } \\
\text { ke kamar irap. }\end{array}$ & & $\mathrm{X}$ & \\
\hline
\end{tabular}

Keterangan, VA : Value Added Activity ;NVA : Non Value Added Activity; NNVA : Necessary Non Value Added Activity

\section{Identifikasi Waste}

Kuesioner digunakan untuk memperoleh informasi berkaitan dengan waste yang terjadi didalam proses pelayanan asien. Terdapat tujuh tipe waste yang diidentifikasi dari proses pelayanan, yaitu: overproduction, waiting, exsesive transportation, inappropriate processing, unnecessary inventory, unnecessary motion, dan defects. Berikut adalah definisi dari tiap-tiap waste dari proses pelayanan pasien :

1. Overproduction

Aktivitas yang terlalu banyak atau terlalu cepat dalam proses pelayanan pemeriksaan melebihi yang dibutuhkan dan menyebabkan penumpukan. Contoh: rekam medis atau hasil laboratorium yang dicetak berkali-kali.

2. Waiting

Adanya kondisi yang membuat pasien menunggu dari satu proses ke proses selanjutnya dan tidak ada aktivitas apapun. Contoh: waktu tunggu untuk menerima tindakan dari staf, menunggu obat.

3. Exsesive Transportation

Perpindahan yang dilakukan oleh pelanggan, material atau dokumen informasi yang berlebihan atau terlalu jauh sehingga penyebabkan pemborosan waktu dan tenaga. Contoh: rekam medis yang harus dikirim ke IGD

4. Inappropriate Processing

Adanya ketidak sesuaian antara prosedur kerja yang seharusnya dengan kondisi yang terjadi. Contoh: pencatatan identitas pasien yang dilakukan berulang-ulang di rekam medis

5. Unnecessary Inventory 


\section{Jurnal Manajemen Teori dan Terapan}

Tahun 10. No. 3, Desember 2017

Penyimpanan dokumen, alat, dan bahan atau informasi yang berlebihan dan tidak diperlukan. Contoh: penumpukan obat, penumpukan alat medis, penumpukan rekamn medis pasien.

6. Unnecessary Motion

Aktivitas yang sebenarnya tidak dibutuhkan dalam suatu proses sehingga menyebabkan pemborosan waktu dan tenaga. Contoh: Mencari peralatan medis.

7. Defect

Kesalahan dari aktivitas yang menyebabkan terjadinya kegagalan atau kecacatan proses tertentu. Sehingga memerlukan pengerjaan ulang. Contoh: dokter salah memberi obat.

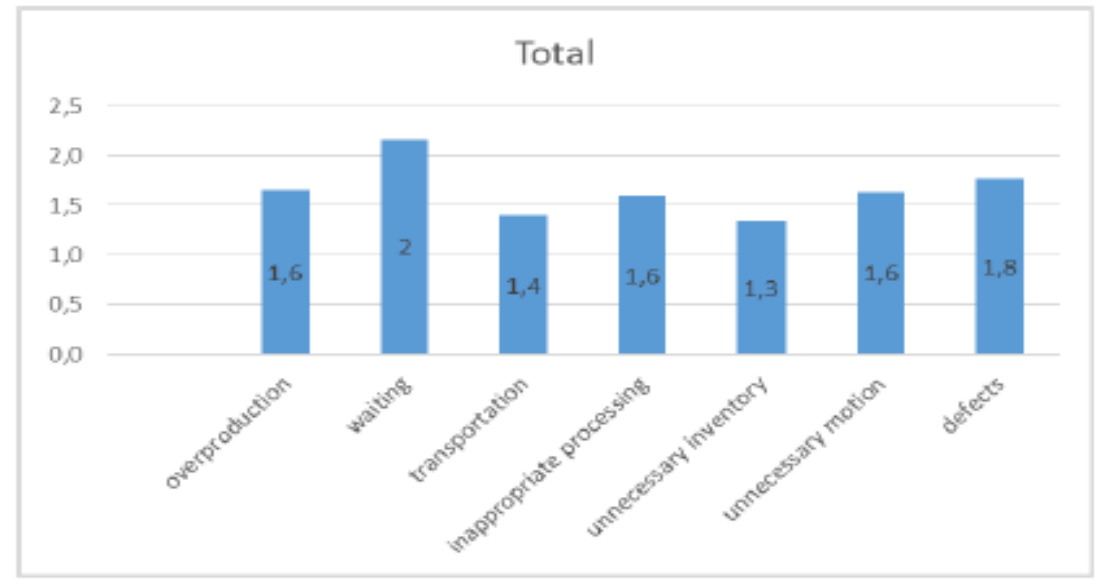

Gambar 2. Pembobotan waste

Tipe pemborosan yang memiliki bobot paling besar adalah waiting dengan skor 2 kemudian defect 1.8, urutan ketiga overproduction, unnecessary motion, dan inappropriate processing dengan skor 1.6, berikutnya terdapat transportation dengan skor 1.4, dan terakhir unnecessary inventory.

\section{Value Stream Analysis Tool (VALSAT)}

Hasil dari scoring dari kuesioner akan dimasukkan dalam tabel VALSAT dan kemudian diproses lebih lanjut menggunakan tabel korelasi antara waste dan 7 mapping tools. Menghitung nilai yang dihasilkan pada tiap-tiap mapping tool, bobot dari waste yang sudah di dapat dari responden dikaitkan dengan nilai korelasi yang ada $(H=9, M=3, L=1)$ kemudian di jumlahkan.

Tabel 3 Hasil Perhitungan VALSAT

\begin{tabular}{|c|c|r|r|}
\hline No. & Value Stream Mapping Tools & $\begin{array}{c}\text { Total } \\
\text { Bobot }\end{array}$ & \multicolumn{1}{l|}{ Ranking } \\
\hline 1 & Process Activity Mapping & 65,07 & 1 \\
\hline 2 & Supply Chain Response Matrix & 19,24 & 3 \\
\hline 3 & Production Variety Funnel & 10,60 & 5 \\
\hline 4 & Quality Filter Mapping & 3,24 & 6 \\
\hline 5 & $\begin{array}{c}\text { Demand Amplification } \\
\text { Mapping }\end{array}$ & 22,37 & 2 \\
\hline 6 & Decision Point Analysis & 15,61 & 4 \\
\hline 7 & Physical Structure Mapping & 2,74 & 7 \\
\hline
\end{tabular}




\section{Indrianawati Usman Mira Ardiyana}

Process Activity Mapping mendapatkan nilai tertinggi sehingga mapping tool tersebut dapat digunakan dalam proses selanjutnya yaitu detailed mapping terhadap value stream. Dari penggambaran process activity mapping didapatkan hasil bahwa proses pelayanan pasien menjadi aktivitas mulai dari mementukan triage pasien hingga pasien dibperbolehkan keluar dari IGD. Seluruh aktivitas pelayanan ini membutuhkan total waktu 62 menit dengan waktu rata-rata dari seluruh total waktu pelayanan 35 pasien yang menjadi acuan. Pengelompokan aktivitas menghasilkan aktivitas operasi (O), aktivitas inpeksi (I), aktivitas transportasi (T), dan aktivitas delay (D). Terdapat aktivitas yang terkategori VA (Value added) dan NVA ( Non Value Added).

Tabel 4

Process Activity Mapping Proses Pelayanan Pasien di IGD

\begin{tabular}{|c|c|c|c|c|c|c|c|}
\hline \multicolumn{7}{|c|}{ Proses Activity Mapping } & \\
\hline \multirow{2}{*}{ No. } & \multirow{2}{*}{ Aktivitas yang dilakukan } & \multirow{2}{*}{ Aliran } & \multirow{2}{*}{$\begin{array}{l}\text { Waktr } \\
\text { (menit) }\end{array}$} & \multicolumn{3}{|c|}{ Kategori } & \\
\hline & & & & VA & NVA & NNVA & \\
\hline 1 & $\begin{array}{l}\text { Perawat menentukan } \\
\text { triage dari pasien yang } \\
\text { datang ke IGD. }\end{array}$ & 0 & 1 & 1 & & & \\
\hline 2 & Diagnosa dokter jaga. & 0 & 2 & 2 & & & \\
\hline 3 & $\begin{array}{l}\text { Keluarga pasien mengisi } \\
\text { da flar administrasi } \\
\text { pasien. }\end{array}$ & 0 & 1 & 1 & & & \\
\hline 4 & $\begin{array}{l}\text { Pemeriksaan dan } \\
\text { tindakan }\end{array}$ & 0 & 19 & 19 & & & \\
\hline 5 & $\begin{array}{l}\text { Pasien berpindah ke } \\
\text { instalasi lain } \\
\text { (laboraturium atau } \\
\text { radiologi) }\end{array}$ & $\mathrm{T}$ & 5 & & & 5 & \\
\hline 6 & $\begin{array}{l}\text { Menunggu hasil dari } \\
\text { instalasi lain }\end{array}$ & D & 6 & & 6 & & \\
\hline 7 & $\begin{array}{l}\text { Dokter jaga menjelaskan } \\
\text { hasil dari laboraturium } \\
\text { atau radiologi kepada } \\
\text { pasien }\end{array}$ & 0 & 2 & & 2 & & \\
\hline 8 & $\begin{array}{l}\text { Menunggu obat dari } \\
\text { apotek }\end{array}$ & $\mathrm{D}$ & 13 & & 13 & & \\
\hline 9 & $\begin{array}{l}\text { Perawat memberikan } \\
\text { daftar rincian obat dan } \\
\text { peralatan yang } \\
\text { digunakan pasien ke } \\
\text { pihak administrasi }\end{array}$ & I & 3 & 3 & & & \\
\hline 10 & $\begin{array}{l}\text { Pasien menunggu untuk } \\
\text { diperbolehkan pulang } \\
\text { atau berpindah ke karmar } \\
\text { inap. }\end{array}$ & $\mathrm{D}$ & 10 & & 10 & & \\
\hline & Total Waktı & & 62 & 26 & 31 & 5 & \\
\hline & Persentase & & $100 \%$ & $42 \%$ & $50 \%$ & $8 \%$ & \\
\hline
\end{tabular}




\section{Jurnal Manajemen Teori dan Terapan \\ Tahun 10. No. 3, Desember 2017}

\section{PEMBAHASAN}

Jenis pemborosan yang memiliki bobot paling tinggi adalah waiting atau waktu menunggu dari satu aktivitas ke aktivitas berikutnya. Dalam process activity mapping dideteksi waiting sebagai pemborosan yang ditunjukkan dengan adanya aktivitas delay. Aktivitas ini memiliki presentase sebanayak $30 \%$ dari 10 aktivitas yang ada didalam proses pelayanan pasien. Memiliki presentasi sebesar $50 \%$ dari total waktu proses pelayanan pasien sehingga aktivitas ini harus dikurangi agar tidak mengganggu proses pelayanan pasien.Pemborosan yang memiliki bobot tinggi berikutnya adalah defect atau cacat. Defect yang terjadi di IGD berbagai macam jenisnya. Dapat dikarenakan lalainya petugas kepada proses layanan sehingga menyebabkan kesalahan.Berdsasarkan atas analisis fish bone yang dilakukan dapat diidentifikasikan akar penyebab masalah yang terjadi. Pemborosan karena menunggu disebabkan oleh pertama, jumlah pasien yang menumpuk dan tidak tedapat tenaga yang membantunya. Kedua, disebankan oleh lamanya pengiriman obat dari apotik. Ketiga adalah lamanya hasil dari laborarium. Untuk mengatasi permasalahan tersebut, maka solusi yang diusulkan adalah menambah tenaga kerja pada shift yang sangat padat dan menyediakan staf kusus untuk membantu mengarahkan pasien. Lama waktu pengiriman obat dari apotik diatasi dengan melakukan pengolahan obat saat hasil dari laboratorium telah keluar. Untuk mengatasi lama waktu pencetakan hasil laboratorium dapat diselesaikan dengan cara mengirim secara langsung hasil laboratorium ke dokter unit gawat darurat melalui jaringan internet internal. Pemborosan yang kedua adalah terjadinya defect pertama adalah karena kurangnya koordinasi, petugas kurang teliti, tidak melakukan pengecekan pasien, tidak memastikan obat untuk pasien, kesalahan pengisian formulir hasil laboratorium. Selanjutnya sebab karena identitas pasien tidak sesuai dan kesalahan pemasangan alat (misalnya kateter). Solusi yang dapat ditempuh untuk mengatasi sebab pemborosan adalah degan melakukan pengecekan ulang berkenaan dengan pasien dan dokumen. Misalnya sebelum melakukan foto rontgen dipastikan pasien bisa di foto, misalnya pasien tidak dalam kondisi tidak hamil

\section{KESIMPULAN}

Berdasarkan hasil penelitian yang sudah dilakukan dan sudah dibahas pada bab-bab sebelumnya, dapat diambil kesimpulan bahwa alur proses pelayanan pasien di IGD sangat fleksibel karena penanganan setiap pasien berbeda-beda dan membutuhkan waktu yang berbeda-beda pula. Waste yang terideintifikasi pada proses pelayanan pasien di IGD berdasarkan data internal tahunan adalah waiting, defect dan inappropriate process. Dan ketiga waste tersebut memiliki bobot tertinggi dalam waste workshop dimana waiting memiliki skor rata-rata 2, kemudian defect memiliki skor rata-rata 1,8 dan terakhir defect dengan skor rata-rata 1,6. Hasil dari Process Activity Mapping ditunjukkan total aktiivtas dalam proses pelayanan pasien berjumlah 10 aktivitas yang terdiri dari 5 aktivitas value added, 4 akitivitas non value added, dan 1 aktivitas necessary non value added. Total leadtime proses pelayanan pasien adalah 62 menit yang terdiri dari 26 menit aktitas value added, 31 menit aktivitas non value added, dan 5 necessary no value added. Usulan perbaikan yang dapat diberikan peneliti untuk setiap pemborosan yaitu, menunggu (waiting), kesalahan dalam pelayanan (defect) dan proses yang tidak layak. Beberapa usulan seperti yang telah disampaikan dapat dipertimbangkan ditambah dengan peningkatan ketrampilan para petugas untuk mengurangi potensi kesalahan 
Indrianawati Usman

Mira Ardiyana

\section{DAFTAR PUSTAKA}

Agustiningsih, A., 2011. Desain Perbaikan Proses Pelayanan Unit Rawat Jalan Dengan Konsep Lean Hospital Di Rumah Sakit Karya Bhakti. Depok: Fakultas Kesehatan Masyarakat Universitas Indonesia.

Chase.R.B, J.F.. and, 2018. Operations and Supply Chain Management 15th ed., New York, NY 10121: Mc.Graw-Hill Education International Edition.

Gaspers.V \& Fontana.A., 2011. Lean Six sigma for manufactring and Service Industries., Jakarta: PT Gramedia Pustaka Utama.

Graban, M. 2009, 2009. Lean Hospital: Improving Qualit, Patient Safety, and Employee Satisfaction, New York: CRC Press.

Hines, P., \& Rich, N., 1997. The seven value stream mapping tools. International journal of operations \& production management. , 17(1), pp.46-64.

Kodra, A.A., 2013. Skripsi: Identifikasi Waste (Pemborosan) Serta Usulan Perbaikan di Instalasi Farmasi Dengan Menggunakan Fishbone Diagram dan Lean Hospital di Rumah Sakit Islam Surabaya.

Pertiwi, N.K., Skripsi: Lean Hospital Sebagai Usulan Perbaikan Sistem Rack Addressing dan Order Picking Gudang Logistik Perbekalan Kesehatan Rumah Sakit Islam Jakarta Cempaka Putih. Depok: Fakultas Kesehatan Masyarakat Universitas Indonesia. 2012.

Womack, James. P and Jones, D.T., 2000. Lean Thingking: Banish Waste and Create Wealth in Your Corporation, New York. 